\title{
CONHECER O ALUNO: \\ CONDIÇÃO NECESSÁRIA PARA UMA REFORMA EDUCATIVA \\ DE QUALIDADE
}

\author{
CONOCER AL ALUMNO: \\ CONDICIÓN NECESARIA PARA UNA REFORMA EDUCATIVA \\ $D E C A L I D A D$
}

\author{
Ausenda Costa, Portugal \\ Jorge Baeza, Chile
}

\section{INTRODUÇÃO}

As exigências próprias da sociedade de informação e conhecimento fazem com que os diferentes países do mundo tenham vindo a colocar cada vez com maior ênfase, entre as suas temáticas principais de preocupação, a realização de reformas educativas. Esta é uma realidade presente tanto no velho como no novo continente : Europa e América Latina. Conjuntamente com esta característica comum, um aspecto que se repete nas reformas educativas é a fraca preocupação com o conhecimento e com a importância do aluno; esta situação agrava-se, particularmente, no ensino secundário que, se bem que varie de um país para o outro, para efeitos de comparação internacional, se refere ao grupo etário que se situa entre os 1314 e os 17-18 anos de idade. Ao fazermos uma análise retrospectiva do que tem sido feito nos últimos anos em Portugal e no Chile no sentido de modificar a Escola e, consequentemente, a qualidade do ensino oferecido aos jovens, somos levados a concluir que as reformas não têm considerado suficientemente os estudantes.

As reformas surgem perante eles como algo que thes é totalmente desconhecido. Os reformadores tendem a definir perfis e metas que aos alunos só lhes cabe cumprir. Consequentemente, o aluno, causa primeira da existência da Escola, acaba por se sentir, somente,

\section{INTRODUCCIÓN}

Las exigencias propias de la sociedad del conocimiento y la información, hacen que los diferentes países del mundo hayan ido colocando cada vez con mayor fuerza entre sus temáticas principales de preocupación, la realización de reformas educacionales. Ello es una realidad presente en el viejo como en el nuevo continente: Europa y América Latina. Pero junto a esta común característica, un aspecto que se reitera en las Reformas Educacionales es la baja preocupación por el conocimiento y consideración del alumno; lo que se agrava en el caso de la Educación Secundaria, la que si bien varia de un país a otro, para efectos de comparación internacional, hace referencia al grupo etareo que se ubica entre los 13-14 y los 17-18 años de edad. Si hacemos un análisis retrospectivo de lo que se ha realizado en los últimos años en Portugal y en Chile, en el sentido de modificar la Escuela, y consecuentemente la calidad de la Enseñanza ofrecida a los jóvenes, debemos llegar a concluir que las reformas no han considerado suficientemente a los estudiantes.

Las reformas surgen ante ellos como algo totalmente desconocido. Los reformadores tienden a definir perfiles y metas que a los alumnos sólo les cabe cumplir. Consecuentemente, los alumnos, causa primera de la existencia de la Escuela, 
como objecto de sucessivas experimentações.

Com estabelece a UNESCO (2002), "os alunos não são o objecto da educação mas sujeitos com direito a uma educação que potencie ao máximo o seu desenvolvimento como pessoas, e Ihes permita inserir-se e influir na sociedade em que estão imersos" (pg.10) .Não obstante, o Projecto Regional da UNESCO sustenta que " persiste uma cultura muito instalada que considera os alunos como meros receptores e reprodutores de informação e não como sujeitos activos na construção de conhecimentos" (pg. 10). "A educação - afirma a UNESCO- deve ter como centro os alunos e considerá-los como protagonistas da sua aprendizagem e não como receptores do ensino"(pg. 15) .

É urgente conhecer em profundidade o que o aluno pensa da Escola e o que dela espera, bem como as suas aspirações, os seus códigos e os seus valores de referência, e, posteriormente, considerar estes dados como básicos, na elaboração das reformas dos sistemas educativos . Neste artigo, analisamos o que é ser aluno, hoje, em Portugal e no Chile, e procuramos tirar, dessa análise, algumas implicações que consideramos poderem constituir um contributo para um efectivo conhecimento e respeito do aluno.

\section{1) MASSIFICAÇÃO DO ENSINO SECUNDÁRIO E MUDANÇAS CULTURAIS NA INSTITUIÇÃO ESCOLAR}

Como a maioria dos países, Chile e Portugal vivem ou viveram um processo de massificação do ensino secundário, processo que não só implica um aspecto quantitativo, mas que trás consigo profundas mudanças culturais no aluno, na escola e no sistema educativo em geral; mudanças, muitas delas, ainda não assumidas. acaban por sentirse sólo como un objeto.

Como lo establece la UNESCO (2002) ${ }^{1}$, "los alumnos no son el objeto de la educación sino sujetos de derechos a una educación que potencie al máximo su desarrollo como personas, y les permita insertarse e influir en la sociedad en la que están inmersos" (p. 10). Pero, sin embargo, sostiene el Proyecto Regional de UNESCO, "todavía persiste una cultura muy instalada de considerar a los alumnos como meros receptores y reproductores de información y no como sujetos activos en la construcción de conocimientos" ( $p$. 10). "La educación -afirma UNESCO- ha de tener como centro a los alumnos y considerarlos como protagonistas de su aprendizaje y no como receptores de la enseñanza. (p. 15)

Es urgente conocer con profundidad lo que el alumno piensa de la Escuela y lo que espera de ella, cuáles son sus aspiraciones, sus códigos y sus valores de referencia $y$, posteriormente, considerar estos datos como básicos, en la elaboración de las reformas de los sistemas educativos. En este artículo analizaremos lo que es ser alumno, hoy, en Portugal y en Chile, y procuraremos de este análisis establecer algunas implicancias que consideramos pueden constituir una contribución para un efectivo conocimiento y consideración del alumno.

\section{1) MASIFICACIÓN DE LA EDUCACIÓN SECUNDARIA Y CAMBIOS CULTURALES EN LA INSTITUCIÓN ESCOLAR}

Como en la mayoría de los países, Chile y Portugal viven o han vivido un proceso de masificación de la educación secundaria, proceso que no sólo implica un aspecto cuantitativo, sino que trae consigo profundos cambios culturales en el alumno, en la institución escolar y en el sistema ediscativn en ceneral Pronesos mishos de ellos

\footnotetext{
${ }^{1}$ UNESCO: Proyecto Regional de Educación para América Latina y el Caribe. Primera reunión intergubernamental del Proyecto Regional, La Habana, Cuba, 14-16 de noviembre, 2002.
} 


\subsection{No aluno}

A massificação do ensino secundário contribui no imediato para a "criação" de juventude". Hoje, cada vez mais, os integrantes do grupo etário que frequenta o ensino secundário podem adiar a sua passagem às responsabilidades da vida adulta. Prolonga-se assim, no tempo, uma maior dependência familiar, um ingresso mais tardio no mundo laboral e um adiamento da saída da família de origem. $O$ que referimos no parágrafo anterior foi originando, paulatinamente, uma estreita associação entre ensino secundário e juventude. A vida quotidiana de uma população cada vez mais alargada está estruturada em função da condição de estudante. O mundo intersubjectivo criado nos estabelecimentos de ensino, e os endogrupos que neles se constituem, tornam como "normal "à vida juvenil a vivência escolar.

A fácil associação entre ensino secundário e juventude gera uma primeira consequência social: "quem não está integrado no sistema escolar está em falta". O não estar presente no mecanismo principal de integração social, a Escola, considera-se - com grande leviandade - como um desvio ao ideal social. Obviamente esta é uma consequência de tipo quantitativo, que simplifica a realidade uma vez que se parte da convicção de que a maioria é a normalidade e as excepções são desvios da norma.

A massificação do ensino secundário não é um processo onde se avança ou se avançou de forma idêntica em todos os grupos sociais. Quem maioritariamente está fora do sistema, são os jovens das classes desfavorecidos da população. No caso do Chile e Portugal, onde o processo de massificação ainda está em marcha, a distância entre grupos sociais, embora se estreite com o tempo, ainda apresenta um claro hiato .

A juntar ao que referimos anteriormente, constata-se que a capacidade de integração do cictoma edırativn nãn vai a nar $\mathrm{nnm}$ a cı a educativo en general. Procesos muchos de ellos aún no asumidos.

\section{1.- En el alumno}

La masificación de la secundaria contribuye en lo inmediato a la creación de juventud. Hoy cada vez más, los integrantes del grupo etáreo que recibe la Educación Secundaria, pueden prolongar su paso a las responsabilidades de la vida adulta. Se prolonga a través del tiempo una mayor dependencia familiar y un más tardío ingreso al mundo laboral y salida de la familia de origen. Lo anterior, ha ido generando paulatinamente una fuerte asociación entre educación secundaria $y$ juventud. La vida cotidiana, de una población cada vez mayor, esta estructurada en función de su condición de estudiantes. El mundo intersubjetivo creado al interior de los establecimientos escolares, y los endogrupos que en él se conforman, hacen como "naturales" a la vida juvenil la vivencia escolar.

La fácil asociación entre educación secundaria y juventud, genera un primera consecuencia social: "quien no esta integrado al sistema escolar está en falta". El no estar presente en el mecanismo principal de integración social, la escuela, se juzga -con gran liviandad- como una desviación al ideal social. Obviamente esta es una consecuencia de tipo cuantitativa, que simplifica la realidad, donde se parte del dato de que la mayoría es la normalidad y las excepciones, desviaciones a la norma.

La masificación de la secundaria no es un proceso donde se avanza o se avanzó en todos los grupos sociales de idéntica forma. Quienes mayoritariamente están fuera del sistema, son jóvenes de sectores pobres. En el caso de Chile y Portugal, donde el proceso de masificación aún esta en marcha, la diferencia entre grupos sociales, si bien se estrecha con el tiempo, aún da cuenta de una clara brecha entre los mismos 
sistema educativo não vai a par com a sua capacidade de retenção, o que origina abandono escolar; este abandono gera um sentimento de perda, dado o alto reconhecimento da Escola como o principal lugar para o jovem adquirir autoestima e reconhecimento social.

\section{$1.2 \mathrm{Na}$ Escola}

A massificação do ensino secundário constitui por outro lado um processo, que é experienciado pela Escola, com uma lenta capacidade de resposta no que se refere à capacidade de se modificar para se adaptar às mudanças produzidas. Dado que, durante anos, o ensino secundário foi privativo de uma elite e de alguns bolseiros, mantém-se uma imagem canónica do aluno, que ficou desfasada com a chegada à Escola de uma população com características diferentes.

Mantém-se no ensino secundário uma ideia dos alunos como sujeitos sem grandes responsabilidades, o que é próprio de sectores bem instalados da sociedade. Daqui que alguns programas escolares não considerem situações laborais (ou necessidades específicas de algumas estações do ano no campo) ou de maternidade precoce .

A situação complexifica-se ainda mais, quando se tendem a extrapolar métodos, pertinentes para o trabalho com crianças, para um grupo de idade juvenil. O aumento dos anos de ensino primário obrigatório ( de 6 para 8 anos no caso do Chile e de 6 para 9 em Portugal) tem tendido para uma infantilização dos que estão nos últimos anos do ensino básico, quando na realidade possuem uma idade própria do universo juvenil.

Á excepção das crianças nas escolas, em que se vive uma "continuidade relativa" entre o estatuto de criança e o estatuto de aluno, os adolescentes desenvolvem uma subjectividade não
Se agrega a lo anterior, que la capacidad del sistema, no va a la par en cuanto a integración y posibilidad de retención, situación que trae consigo -unido a lo antes dicho- que la deserción del sistema genera un sentimiento de perdida, dado el alto reconocimiento de la escuela como el principal lugar para el logro de una identidad juvenil positiva sobre sí mismo y reconocida socialmente.

\subsection{En la institución escolar}

La masificación de la educación secundaria constituye por lo demás un proceso, que es experimentado por la institución escolar, con una lenta capacidad de respuesta en lo que se refiere a capacidad de modificación para adaptarse a los cambios producidos. Dado que por años, la educación secundaria fue privativa de una elite y de unos pocos becarios, se mantiene una imagen canónica del alumno, que queda desfasada con la llegada de una población de características diferentes.

Se mantiene en la educación secundaria una visión de los alumnos como sujetos sin mayores responsabilidades, lo que es propio de sectores acomodados de la sociedad. De aquí que algunas programaciones escolares no consideren situaciones laborales (o requerimientos propios de algunas estaciones del año en el campo) o de maternidad a temprana edad.

Situación que se aún más compleja, cuando se tiende a extrapolar modos pertinentes para el trabajo con niños a una grupo en edad juvenil. El aumento de los años de educación primaria obligatoria (de 6 a 8 años de educación básica en el caso de Chile y de 6 a 9 en Portugal ) ha tendido a una infantilización de quienes están en los últimos años de básica, cuando en realidad poseen una edad propia del mundo juvenil.

A diferencia de los niños en las escuelas, que viven una "continuidad relativa" entre su estatuto de niño y su estatuto de alumno, los 
escolar. Formam-se assim uma subjectividade e uma vida colectiva independentes do colégio ou escola, que afecta a própria vida escolar e, inclusivamente para alguns adolescentes, não resulta fácil conseguir articular de forma satisfatória estes dois espaços de vida, o que gera no mesmo indivíduo uma tensão entre o estudante e o adolescente .

\subsection{No sistema educativo}

Além das mudanças e tensões que vimos enunciando, a massificação do ensino secundário gera nas famílias cujos filhos chegam pela primeira vez à escola um conjunto de expectativas. Estas expectativas acabam por se gorar quando pais e filhos são confrontados com a realidade. Efectivamente, a actual desvalorização da escolaridade secundária leva a que os esforços familiares não se vejam compensados, como o eram quando só uma minoria concluía o ensino secundário.

A desvalorização da escolaridade secundária, em comparação com os tempos anteriores à sua massificação, implica, por outro lado, uma perda do sentido e do significado social que tinha nas suas origens. Depois de uma responsabilidade de formação de elites (os "herdeiros", sustentam alguns), converteu-se numa "obrigatoriedade" social, (não necessariamente obrigatoriedade jurídica) que se torna cada vez mais comum completar. Esta perda de significado social não é alheia ao processo interno que vive o próprio estudante, que ao contrário de quando frequentava o ensino primário, desenvolveu a capacidade para se perguntar qual o sentido e significado das instituições em que participa. A resposta a esta pergunta, estabelecida no próprio aluno, vai constituir, muitas vezes, a explicação dos comportamentos de enfado que manifesta na sua vida escolar. adolescentes desarrollan una subjetividad no escolar. Se forma una subjetividad y una vida colectiva independientes del colegio o liceo, que afecta a la vida escolar misma, e incluso para algunos adolescentes, no resulta fácil lograr articular de forma satisfactoria estos dos espacios de vida, lo que genera en un mismo sujeto, una tensión entre el estudiante y el adolescente.

\subsection{En el sistema educativo}

La masificación de la secundaria suma a todos los cambios y tensiones anteriores, una realidad de expectativas y frustración para los hijos de las familias que vienen llegando por primera vez. La posibilidad de ingreso a la educación secundaria genera expectativas en los padres, que no dicen relación con una realidad de devaluación de la escolaridad. Situación que trae en los jóvenes la mayor parte de las veces una frustración. Los esfuerzos familiares no se ven compensados, como lo fueron en el momento donde solo una minoría alcanzaba la educación secundaria completa.

La devaluación de la escolaridad secundaria, en comparación con los tiempos previos a su masificación, implica por lo demás, una perdida del sentido y significado social que tenía en sus orígenes. Desde una responsabilidad de formación de las elites (los "herederos", sostienen algunos), se ha convertido en una "obligatoriedad social" (no necesariamente obligatoriedad jurídica) que se hace cada vez más común completarla. Esta perdida de significado social, no es ajena al proceso interno que vive el mismo estudiante que a diferencia de cuando estaba en la educación primaria, ha desarrollado una capacidad para preguntarse por el sentido y significado de las instituciones en las cuales participa. La respuesta a esta pregunta, instalada en el propio alumno, va a constituir la base de explicación, muchas veces, de las conductas de molestia que expresa en su vida escolar. 


\section{2) O QUOTIDIANO DO ALUNO E O SENTIDO DO TRABALHO ESCOLAR}

A evolução da tecnologia transformou profundamente os contextos em que se inserem as escolas e, consequentemente, o quotidiano dos alunos. Efectivamente, os jovens dispõem hoje de uma enorme variedade de objectos electrónicos tais como calculadoras, vídeos, computadores, que aumentaram, exponencialmente, as suas fontes de informação, manipulação e aprendizagem. Esta enorme multiplicação de meios para que a escola faça sentido, implica uma profunda reformulação desta bem como a remodelação do seu apetrechamento.

Ao viverem numa sociedade de informação e conhecimento, os alunos dispõem, assim, de múltiplas formas de acesso ao conhecimento, geralmente mais motivadoras do que as que lhes são apresentadas nas salas de aula, o que obriga a uma reflexão profunda sobre as metodologias de ensino praticadas pelos docentes.

Fazer sentido para o aluno significa que as tarefas escolares e todas as actividades que 0 aluno realiza na Escola ou para a Escola se insiram de alguma forma na sua prática de vida. Nesta ordem de ideias, a construção de sentido terá, necessariamente, de se articular com as várias culturas que moram no aluno, ou seja, a cultura que teve origem na sua família, no seu meio social e a que se originou na vivência com os seus companheiros

\section{3) A DISTÂNCIA ENTRE A CULTURA ESCOLAR E A CULTURA JUVENIL}

Se bem que a idade de frequência do ensino secundário seja própria da idade juvenil, uma boa parte da organização das escolas secundárias, bem como das políticas a este nível, são delineadas ignorando os jovens. Desta forma a cultura escolar não só não integra a cultura iıvenil mas muitas veres lhe fecha as nortas e the

\section{2) EL COTIDIANO DEL ALUMNO Y EL SENTIDO DEL TRABAJO ESCOLAR}

La evolución de las tecnologías ha transformado profundamente el contexto en que se inserta la escuela $y$, consecuentemente, el cotidiano de los alumnos. Efectivamente, los jóvenes disponen hoy de una enorme variedad de objetos electrónicos tales como calculadoras, vídeos, computadores, que aumentan, exponencialmente, sus fuentes de información, manipulación y aprendizaje. Esta enorme multiplicación de medios para que la escuela tenga sentido, implica una profunda reformulación de ella, como también de la remodelación de equipamiento.

Hoy vivimos en una sociedad de información y conocimiento, donde los alumnos disponen de múltiples formas de acceso al conocimiento, generalmente más motivadoras que las presentadas en la sala de clases, lo que obliga a reflexionar profundamente sobre las metodologías de enseñanza practicada por los docentes.

Hacer sentido para el alumno, significa que las tareas escolares y todas las actividades que el alumno realiza en la Escuela o para la Escuela, se inspiran de alguna forma en su práctica de vida. En este orden de ideas, la construcción de sentido tendrá que ser necesariamente articulada con las varias culturas que habitan en el alumno, la cultura que tiene origen en su familia, en su medio social y las que se originan en las vivencias con sus compañeros.

\section{3) LA DISTANCIA ENTRE LA CULTURA ESCOLAR Y LA CULTURA JUVENIL}

Si bien la edad de cursar la educación secundaria, es la propia de la edad juvenil, buena parte del ordenamiento de los establecimientos escolares de secundaria, como también de las políticas de este nivel, se construyen ignorando a los jóvenes. De esta forma la cultura escolar no 
juvenil, mas muitas vezes lhe fecha as portas e lhe vira as costas.

A distância entre a cultura escolar e a cultura juvenil converte, muitas vezes, as escolas em espaços formativos surdos e descontextualizados : não escutam os jovens que são seus alunos, nem consideram a sua realidade histórica e social. Experiencia-se a interacção pedagógica sem considerar o aluno como sujeito autónomo, situado num tempo e num espaço que, se bem que o não determine, o condiciona fortemente.

Paradoxalmente, a não consideração do contexto inverte-se totalmente no momento em que os educadores explicam as causas dos elevados níveis de insucesso escolar dos seus alunos como sendo da responsabilidade destes e da falta de apoios, tanto familiar como do seu contexto social .

Muitas vezes "fala-se deles", dos jovens, mas poucas vezes se "fala com eles". Esta falta de diálogo com os alunos ou as alunas, agravada em países como o Chile e Portugal pelo número de alunos por sala e o número de horas lectivas dos professores, conduz a uma visão dos alunos altamente simplificada, que se traduz numa homogeneização dos alunos em que desaparece a pessoa e se vê estritamente o aluno; a distinção dos alunos é baseada em estereótipos e na presunção de que os alunos e as alunas só actuam correctamente quando vigiados. Hoje reconhece-se o valor da diversidade, mas não se aceita com facilidade a pluralidade dos jovens tratando-os como uma massa uniforme em que cada um deles carece de uma identidade própria.

A situação enunciada no parágrafo anterior, que conduz a uma falta de aprofundamento da identidade de cada jovem, é ainda mais agravada pela alta valorização atribuída aos conteúdos programáticos, em detrimento do autoconhecimento do aluno. O desenvolvimento solo no integra a la cultura juvenil, sino que muchas veces le cierra las puertas y le da su espalda.

La distancia entre la cultura escolar y la cultura juvenil, convierte a los establecimientos escolares -en más de una ocasión- en espacios formativos sordos $y$ descontextualizados: no escuchan a los jóvenes que son sus alumnos, ni consideran su realidad histórica y social. Se experimenta la interacción pedagógica sin considerar al alumno como un sujeto autónomo, situado en un tiempo y un espacio que si bien no lo determina, lo condiciona poderosamente.

Paradojalmente esta no consideración del contexto, se revierte totalmente al momento de explicar por parte de los educadores, las causas de los bajos niveles de logros de sus alumnos, donde la principal causa de explicación es la propia responsabilidad del estudiante 10 desresponsabilidad), acompañada por la falta de apoyo familiar y de su contexto social.

Muchas veces se "habla de ellos", de los jóvenes, pero pocas veces se "habla con ellos". Esta falta de diálogo con los alumnos(as) agravada en países como Chile y Portugal por la cantidad de estudiantes por salas y la cantidad de horas docentes de los profesores(as)- conduce a una visión sobre los alumnos altamente simplificada, que se expresa en una homogenización de los estudiantes, donde desaparece la persona y se ve restrictivamente como alumno; un etiquetar a los alumnos haciendo distinciones entre ellos a partir de estereotipos y en una desconfianza en los alumnos y alumnas, ya que se cree que el joven sólo actuará correctamente si es vigilado. Hoy se reconoce el valor de la diversidad, pero aún no se acepta con facilidad la pluralidad de los jóvenes y se les sigue tratando como una masa uniforme de alumnos que carece cada uno de ellos de una identidad propia.

Esta situación, enunciada en el párrafo 
afectivo dos alunos, não constitui um tema central de preocupação e não the é atribuída igual importância à dos conteúdos disciplinares que integram os currículos do ensino secundário.

A disciplina continua a ser o elemento que medeia entre a cultura escolar e a cultura juvenil. $\mathrm{O}$ elemento ordenador da convivência escolar- na maioria dos estabelecimentos de ensino - é a disciplina, o que se traduz numa prática unidireccional de um claro fundamento adultocêntrico. Situação que não tem tanto relação com os adultos em si mesmos, mas com a matriz em que esta prática se insere, que assume um estilo de relação assimétrica (que inclusivamente ocorre entre os alunos). Não é um problema de gerações, mas de atitudes, discursos e estilos, que vão configurando e dando vida a uma forma particular de relação, onde predomina a verticalidade e a assimetria.

Não obstante 0 que afirmámos anteriormente, não se pode deixar de reconhecer que, cada vez mais, se torna necessário que os professores e os que exercem cargos directivos construam uma legitimidade perante os alunos. A unidireccionalidade já não basta numa sociedade onde há um maior reconhecimento dos direitos individuais. Os alunos reconhecem- se como sujeitos com direitos e fazem-se respeitar. Não se pode deixar de reconhecer, a este respeito, que entre os fenómenos que surgiram nas últimas décadas se encontra o aparecimento da infância e da juventude como actores protagonistas, o que origina novas pesquisas e reflexões acerca do seu lugar na sociedade, na cultura e na educação. A educação deixou de ser uma prática de transmissão de valores e de códigos das gerações mais velhas, para se tornar numa modalidade de maior autonomia e protagonismo dos alunos e das alunas.

A realidade da cultura juvenil de hoje não está à margem das grandes mudanças culturais a anterior, que conduce a una falta de profundización en la identidad de cada joven, se ve complementada -agravando aún más la situaciónpor la alta valoración que se le otorga al conocimiento escolar (los contenidos impartidos en las actividades curriculares), por sobre el conocimiento de sí mismo por parte del alumno. El desarrollo afectivo de los alumnos(as), no constituye un tema de preocupación central, o de una valoración de igual medida que los contenidos de las diversas disciplinas que conforman el plan de estudios de educación secundaria.

La disciplina sigue siendo el elemento central que media entre la cultura escolar y la cultura juvenil. El elemento ordenador de la convivencia escolar -en la mayoría de los establecimientos- es la disciplina, la que se expresa en una práctica unidireccional de un claro fundamento de carácter adultocéntrico. Situación que no dice tanto en relación con los adultos en sí mismo, sino con la matriz en que ésta práctica se ubica, que asume un estilo de relación asimétrica (que incluso en algunos casos se da entre alumnos). No es un problema de edad, sino de actitudes, discursos y estilos, que van configurado $y$ dando vida a una particular forma de relación, donde prima la verticalidad y la asimetría.

No obstante lo anterior, no se puede dejar de reconocer, que cada vez más, se aprecia la necesidad de los profesores y directivos de construir una legitimidad frente a los alumnos, La unidireccionalidad ya no basta en una sociedad de mayor reconocimiento de los derechos de las personas. Los alumnos se saben sujetos de derechos y se hacen respetar. No se puede dejar de reconocer a este respecto, que entre los fenómenos de las últimas décadas se encuentra la irrupción de la infancia y la juventud como un actor social protagónico, lo que genera nuevas demandas y reflexiones sobre su lugar en la sociedad, la cultura y la educación. La educación daia da car i ina nrántina da trancmición da valnrac 
nível mundial, por isso não prestar atenção à cultura juvenil implica formar pessoas sem considerar o seu contexto. Na sociedade actual, em que têm a primazia as leis do mercado, os jovens são parte delas, nos mais diferentes âmbitos das suas actividades. As organizações estudantis já não reproduzem nos estabelecimentos de ensino os debates presentes na sociedade (estão esvaziadas do antigo sentido político); as relações que 0 aluno(a) médio estabelece com as organizações de estudantes já não é motivada por motivos reinvindicativos, mas por uma relação regulada pelas leis da oferta e da procura, daí que se utilizem as organizações estudantis, de acordo com a oferta que apresentam, mas sem uma identificação importante com elas.

A não consideração da cultura juvenil, na cultura escolar, conjuntamente com as consequências que mencionámos anteriormente, tem um efeito negativo no ambiente escolar e em particular na possibilidade de protagonismo dos estudantes. Uma instituição que acolhe o aluno (a), que lhe oferece oportunidade não só para lhes dar respostas mas também para que participe nas suas decisões, facilita a identificação com a instituição educativa e gera um espaço mais adequado para o desenvolvimento da própria identidade do jovem.

\section{4) SER ALUNO OU ALUNA NÃO É UM PAPEL PASSIVO, MAS UM OFÍCIO QUE SE APRENDE E QUE POSSIBILITA O EXERCÍCIO DA INDIVIDUALIDADE}

Assume-se no discurso pedagógico, cada vez com maior ênfase, que a formação de qualquer "actor social" implica conjuntamente com a socialização (onde o indivíduo interioriza normas e modelos), um processo de subjectivação que permita uma identidade própria. Não obstante esta convicção, a voz e a experiência estudantil, continuam a ficar ofuscadas sob uma representação que encerra uma ideologia de controle e manuseamento, onde, em nome da deja de ser una práctica de transmisión de valores y de códigos de las viejas generaciones, para avanzar a una modalidad de mayor autonomía y protagonismo de los alumnos y alumnas.

La realidad de la cultura juvenil de hoy, no esta al margen de los grandes cambios culturales a nivel mundial, por lo tanto, desatender la cultura juvenil implica formar personas sin consideración de su contexto. En la sociedad presente, de primacía de las regulaciones del mercado, los jóvenes son parte de ello, en los más diversos ámbitos de su quehacer. Las organizaciones estudiantiles, a modo de ejemplo, ya no replican al interior de los establecimientos educacionales los debates presentes en la sociedad (están vaciadas del antiguo sentido político); la relación que establece el alumno(a) medio con las organizaciones estudiantiles, ya no es de una pertenencia motivada por principios reivindicativos, sino la de una relación regulada por las leyes de oferta y demanda, donde se hace "uso" de las organizaciones, se consume de lo que ofrecen, de acuerdo a la oferta que presenta, pero sin una identificación mayor con ella

La no consideración de la cultura juvenil, en la cultura escolar, junto a las consecuencias antes nombradas, tiene un negativo efecto en el clima escolar y en particular en la posibilidad de un protagonismo estudiantil. Una institución que acoge al alumno(a), que le brinda oportunidad no solo para dar respuesta sino que para que participe de sus decisiones, facilita la identificación con la unidad educativa y genera un espacio más adecuado para el desarrollo de la propia identidad del o la joven.

\section{4) SER ALUMNO O ALUMNA NO ES UN ROL PASIVO, SINO UN OFICIO QUE SE APRENDE Y QUE POSIBILITA EL EJERCICIO DE LA INDIVIDUALIDAD}

Si bien hoy se asume en el discurso pedagógico, cada vez con mayor fuerza, que la 
eficiência, da necessidade de se obter sucesso escolar, se ignoram os recursos e as riquezas das histórias de vida de cada um dos alunos.

Se bem que hoje não se possa deixar de reconhecer que assistimos a uma mudança da primazia do sujeito sobre o sistema, pensamos que ainda falta muito para que se assuma universalmente que ser aluno ou aluna constitui algo muito mais amplo que um papel passivo, una definição externa.

Ser aluno ou aluna não é só o desempenho de um papel, um exercício de um conjunto de direitos e deveres para estar numa posição determinada. O papel deve ser aceite só como um instrumento válido para o estudo, mas não deve confundir-se, em momento algum, com o aluno ou aluna como tal. Cada jovem vive a sua experiência de ser estudante de una forma particular e atribui um sentido subjectivo próprio ao trabalho que realiza. No exercício do papel, é sempre possível distinguir entre os aspectos normativos, a sua realização simbólica, e o que realiza uma pessoa numa situação concreta. As escolas, como artefactos humanos, como organizações, permitem sempre aos seus actores uma margem de liberdade de acção, onde o comportamento não é nunca inteiramente previsível e determinado, mas sempre contingente.

Os jovens estudantes do ensino secundário não são sujeitos passivos, nem possuem apenas capacidade para responder às exigências da escola de acordo com o que está tipificado como conduta correcta; as relações que estabelecem com os centros escolares não estão ausentes da sua própria subjectividade. Os alunos e alunas constróem "saberes" e "saber fazer" que lhes permitem dar um sentido e significado próprio ao que realizam. Estes saberes e saber fazer adquirem-no num processo de apropriação que tem formación de cualquier "actor social" implica junto a la socialización (donde el individuo interioriza normas y modelos), un proceso de subjetivación que permite una identidad propia; no obstante ello, la voz y la experiencia estudiantil, sigue quedando disuelta bajo una representación que encierra una ideología de control y manejo, donde en nombre de la eficiencia, de la necesidad de obtener logros escolares, se ignoran los recursos y las riquezas de las historias de vida de cada uno de los alumnos.

Aunque hoy no se puede dejar de reconocer que asistimos a un cambio en la primacía del sujeto por sobre el sistema, al parecer aún falta mucho para que se asuma universalmente, que ser alumno o alumna, constituye algo mucho mayor que un rol pasivo, una definición externa.

Ser alumno o alumna no es solo el ejercicio de un rol, del ejercicio de un conjunto de derechos y deberes por estar en una posición determinada. El rol debe ser aceptado sólo como un instrumento valido para el estudio, pero no debe confundirse, en momento alguno, con el alumno o alumna propiamente tal. Cada joven vive su experiencia de ser estudiante de una forma particular y le otorga un sentido subjetivo propio a la labor que realiza. En el ejercicio del rol, es siempre posible diferenciar entre los aspectos normativos, su realización típica, y la que efectúa una persona en una situación concreta. Los establecimientos escolares, como artefactos humanos, como organizaciones, siempre permiten a sus actores un margen de libertad de acción, donde el comportamiento no es jamás enteramente previsible, no está determinado, siempre es contingente.

Los jóvenes estudiantes de secundaria no son sujetos pasivos, no solo poseen capacidad para responder a las exigencias del establecimiento de acuerdo a lo que éste ha tipificado como conducta correcta. Las relaciones que establecen con sus centros escolares no están ausentes de su propia subjetividad. Los alumnos y alumnas 
como características ser colectivo e contextualizado..

No decurso de meses e anos, o aluno adquire os saberes e saber fazer, os valores, códigos, costumes e atitudes que o converterão num perfeito "nativo" da organização escolar, e que, pelo menos, Ihe permitirão sobreviver sem demasiadas frustrações. Daqui que seja possível falar de um processo de aquisição de um "ofício de aluno", de um processo de aquisição de um conjunto de "regras de jogo", de aprendizagem de estratégias necessárias para viver as regras da vida escolar, sem que, com isso, se eliminem a própria individualidade

A aluna ou o aluno que alcançou o "oficio", conhece por intermédio da sua experiência, ou da dos outros que faz sua, os sinais e os símbolos necessários para se desenvolver correctamente dentro da vida escolar. Aprende em quem ter confiança e de quem sempre desconfiar; aprende como estudar para tal professor ou como "conquistar" este e o outro; conhece os lugares para estar só e não vigiado; consegue elaborar um "mapa" que lhe permite localizar desde onde é mais barato um utensílio escolar, até onde se podem comprar drogas. Ao fim e ao cabo aprende tudo o necessário, para viver a sua experiência escolar sem grande dificuldade, chegando a ouvir o que não se disse e a ver o que outros, "não iniciados", não conseguem ver .

Não conhecer e considerar estes sentidos e significados próprios, como também as estratégias que os jovens desenvolvem para possibilitar o seu protagonismo, leva a explicações erradas ou a um tipo de relação não válida com eles, e inclusivamente à elaboração de políticas educativas inadequadas. Conhecer o aluno é uma condição necessária para uma reforma educativa de qualidade. construyen "saberes" y "saber hacer" que les permite dar un sentido y significado propio a lo que realizan. Estos saberes y saber hacer lo adquieren en un proceso de apropiación que tiene como características ser colectivo y situado.

En el transcurso de meses y años, el alumno adquiere los saberes y saber hacer, los valores y códigos, costumbres y actitudes que lo convertirán en un perfecto "nativo" de la organización escolar, lo que al menos, le permitirá sobrevivir sin demasiadas frustraciones. De aquí que sea posible hablar de un proceso de adquisición de un "oficio de alumno", de un proceso de adquisición de un conjunto de "reglas de juego", de aprendizaje de estrategias necesarias para vivir los requerimientos de la vida escolar, sin que en ello, se elimine la propia individualidad.

La alumna o el alumno que ha logrado el "oficio", conoce por intermedio de su experiencia, o la de otros que hace suya, aquellos signos $y$ símbolos necesarios para desenvolverse con corrección dentro de la vida escolar; aprende en quién tener confianza y de quién siempre desconfiar; aprende cómo estudiar para tal profesor o cómo "conquistar" a este otro; conoce los lugares para estar solo y no vigilado; logra un "mapa" que le permite ubicar desde dónde es más barato un útil escolar, hasta dónde se puede comprar drogas. En fin aprende todo lo necesario, para vivir su experiencia escolar sin mayor dificultad, llegando a oír aquello que no se dice y a ver lo que otros, "no iniciados", no logran ver.

No conocer y considerar estos sentidos $y$ significados propios, como a su vez las estrategias que desarrollan para posibilitar su protagonismo, lleva a explicaciones erradas o un tipo de relación no válida con ellos, e incluso a la elaboración de políticas de atención inadecuada. Conocer al alumno es una condición necesaria para un reforma educacional de calidad. 


\title{
Contactar
}

Revista lberoamericana de Educación

\author{
Principal OEI
}

